\title{
RESPONSABILIDAD SOCIAL DE LA EMPRESA ANALISIS DEL CONCEPTO
}

\author{
Enrique Bour*
}

enviado: Agosto 2012 - aceptado: Septiembre 2012

\section{Resumen}

¿Hay una lógica que contradice al mercado? ¿Puede (o debe) una empresa capitalista desentenderse de otros objetivos de la sociedad? Enfatizando la interpretación normativa de estas afirmaciones, se ofrece una traducción en español del artículo de Milton Friedman publicado en 1970. Este artículo es situado con relación a la literatura, siendo la tesis que los economistas están más inclinados hacia la posición de Friedman; por el contrario, quienes no visualizan el rol del funcionamiento descentralizado de los mercados, enfatizan funciones adicionales que, a juicio del economista, pueden desnaturalizar el papel esencial de una empresa en un sistema económico.

Clasificación JEL: B41, D01, D60, K0

Palabras clave: corporación - partes interesadas - descentralización

\begin{abstract}
Is there a logic that contradicts the market? Can (should) a capitalist enterprise ignore other societal goals? Emphasizing the normative interpretation of these claims, we provide a Spanish translation of Milton Friedman's article published in 1970. This item is located in relation to literature, emphasizing that economists are more inclined to Friedman's position; on the contrary, those who do not display the role of decentralized operation of markets, emphasize additional functions. According to the economists' view the latter approach can distort the role of a company in an economic system.
\end{abstract}

JEL Classification: B41, D01, D60, K0

Keywords: corporation - stakeholders - decentralization

\footnotetext{
* Profesor Titular de la Universidad de Buenos Aires, Investigador Visitante en la Fundación de Investigaciones Económicas Latinoamericanas (FIEL)
} 
"La Sensibilidad Social de la Empresa se refiere a la capacidad de una empresa de responder a las presiones sociales.“(William Frederik) ${ }^{1}$

"La Responsabilidad Social de las Empresas es Maximizar sus beneficios” (Milton Friedman) ${ }^{2}$

\section{INTRODUCCION}

Las dos citas anteriores reflejan dos posturas diametralmente opuestas en cuanto al rol de las empresas en un sistema capitalista. ¿Es esto así? ¿Hay que aceptar la existencia de una lógica que contradice al mercado, o de una lógica según la cual una empresa capitalista puede desentenderse de objetivos de la sociedad?

Repasaré argumentos de distintos economistas, tomando como punto de partida un documento de Milton Friedman, y de sopesar pros y contras. En efecto, especialmente en la literatura administrativa, hay muy pocos documentos que no se refieran a su crítica incisiva a la por entonces (1970) práctica emergente de hablar de responsabilidad social empresaria (de aquí en más, RSE). El objetivo de este documento es 1) disponer de una traducción del artículo de Friedman, que según lo que sé, aún no está en internet; 2) situar dicho artículo con referencia a la literatura, y 3) extraer las principales conclusiones de 1) y 2), en base a la experiencia más reciente de política económica de nuestro país. Mi tesis es que los economistas están en general más inclinados hacia la posición de Friedman; por el contrario, otros científicos sociales que no visualizan el rol del funcionamiento descentralizado de un sistema de mercados, tienden a enfatizar roles suplementarios que, a juicio del economista, pueden terminar desnaturalizando la función esencial de las empresas en un sistema económico. Pondré énfasis sobre el punto de vista normativo.

\footnotetext{
${ }^{1}$ From CSR $_{1}$ to CSR $_{2}$ : The Maturing of Business-and-Society Thought, Univ. of Pittsburgh, 1978

${ }^{2}$ The Social Responsibility of Business is to Increase its Profits, The New York Times Magazine, September 13, 1970
} 


\section{THE SOCIAL RESPONSIBILITY OF BUSINESS IS TO INCREASE ITS PROFITS (TRADUCCION)}

\section{Dice Friedman:}

Cuando escucho hablar a un hombre de empresa, en forma elocuente, sobre la "responsabilidad social de la empresa en un sistema de empresas libres", me acuerdo de unas líneas deliciosas de un francés que descubrió, a los 70 años, que siempre había estado hablando en prosa a lo largo de toda su vida. El empresario cree que está defendiendo a las empresas libres cuando declama que a la empresa no le preocupa "solamente" el beneficio sino también promover fines "sociales" deseables; que la empresa tiene "conciencia social” y que, en consecuencia, se toma en serio sus responsabilidades de dar empleo, eliminar la discriminación, evitar la contaminación y todo lo que esté contemplado en los reclamos de la cosecha contemporánea de los reformistas. En realidad, lo que están haciendo - o harían si alguien los tomara en serio - es predicar puro socialismo. Los empresarios que hablan así son títeres inconscientes de las fuerzas intelectuales que han socavado las bases de una sociedad libre en estas décadas pasadas.

Las discusiones sobre las "responsabilidades sociales de las empresas" son notables por su imprecisión y carencia de rigor. ¿Qué significa que una "empresa" tenga responsabilidades? Solamente las personas las tienen. Una sociedad es una persona artificial y en tal sentido sólo puede tener responsabilidades artificiales, pero de "las empresas" en conjunto no puede decirse que las tengan, aún en sentido impreciso. El primer paso para clarificar la doctrina de la responsabilidad social de las empresas es preguntarse precisamente qué es lo que esto significa.

Presumiblemente, los individuos que deberían ser responsables son los hombres de negocio, es decir los propietarios individuales o los ejecutivos corporativos. Gran parte de la discusión sobre la responsabilidad social está dirigida a las sociedades, por lo cual en lo que sigue dejaré de lado a los propietarios individuales y me concentraré en los ejecutivos corporativos.

En un sistema de propiedad privada de libre empresa, un ejecutivo corporativo es un empleado de los propietarios de la empresa. Tiene responsabilidad directa hacia sus empleadores. Esa responsabilidad consiste en manejar la empresa conforme a sus deseos, que serán en general ganar la mayor cantidad de dinero posible respetando las reglas básicas sociales, tanto las incorporadas en el derecho como en la ética. Obviamente, a veces sus empleadores pueden tener un objetivo distinto. Un grupo de gente podría fundar una sociedad para un fin caritativo - por 
ejemplo, un hospital o una escuela. El administrador no tendría al beneficio monetario entre sus objetivos, sino cumplir con ciertos servicios.

En todo caso, el punto clave es que, teniendo en cuenta su capacidad como ejecutivo corporativo, ese administrador es el agente de los individuos propietarios de la corporación o que han establecido la institución caritativa, y que su responsabilidad es hacia ellos.

Está de más decir que no será fácil juzgar su gestión. Pero por lo menos el criterio de gestión es directo, y las personas entre quienes existe un acuerdo contractual voluntario están claramente definidas.

Naturalmente, el ejecutivo corporativo también es una persona por derecho propio. En cuanto tal, puede tener varias otras responsabilidades que él reconozca o asuma en forma voluntaria - hacia su familia, su conciencia, sus sentimientos de caridad, su iglesia, los clubes de los que es miembro, su ciudad, su país. Puede sentirse impulsado por estas responsabilidades a dedicar una parte de su ingreso a causas que considera valiosas, rechazar trabajar para ciertas corporaciones, y aún dejar su empleo, por ejemplo, para cumplir con sus responsabilidades. Si lo deseamos, podemos referirnos a algunas de estas responsabilidades como "responsabilidades sociales". Pero en tales cuestiones está actuando como principal, no como agente: está gastando su propio dinero o tiempo o energía, no el dinero de sus empleadores o el tiempo y energía que fueron contratados para actuar a su propósito. Si se trata de "responsabilidades sociales", son responsabilidades sociales de individuos - no de las empresas.

¿Qué puede significar que el ejecutivo corporativo tenga una "responsabilidad social” como empresario? Si el enunciado no es pura retórica, se debe querer decir que debe actuar de cierta manera no alineada con los intereses de sus empleadores. Por ejemplo, que debe evitar aumentar el precio del producto a efectos de contribuir al objetivo social de impedir la inflación, aunque aumentar el precio sea del mayor interés de la empresa. $\mathrm{O}$ que debe incurrir en gastos para evitar contaminación más allá del monto que desearía la corporación o los que la ley le exige contribuir para el objetivo social de mejorar el medio ambiente. O que debe contratar a expensas de los beneficios de la corporación a desempleados en lugar de gente mejor calificada para contribuir al objetivo social de reducir la pobreza.

En cada caso, el ejecutivo corporativo estaría gastando el dinero de otros en pos de un interés social general. En la medida que sus acciones - con vistas a su "responsabilidad social" - reducen los rendimientos de los accionistas, está 
gastando el dinero de ellos. En la medida que con sus acciones aumenta el precio a los consumidores, está gastando su dinero. En la medida que con sus acciones reduce los salarios de algunos empleados, está gastando dinero que les pertenece.

Ahora bien, los accionistas, o los consumidores, o los empleados podrían gastar de su propio peculio en una acción particular si así lo desearan. El ejecutivo ejerce una "responsabilidad social" distinta, en lugar de cumplir como agente de los accionistas o de los consumidores o de los empleados, sólo si gasta la plata de modo distinto que lo que ellos hubieran deseado hacer.

Pero si actúa así, es como si estuviera imponiendo efectivamente impuestos, por una parte, y por la otra, decidiendo cómo debería ser gastada la recaudación.

Este proceso da lugar a cuestiones políticas a dos niveles: principios y consecuencias. En materia de principios políticos, fijar impuestos y gastar su recaudación son funciones del gobierno. Hemos definido elaboradas consideraciones constitucionales, legislativas y judiciales para controlar estas funciones, a fin de asegurar que sean fijados impuestos en la medida posible con arreglo a las preferencias y deseos del público - después de todo, "impuestos sin representación” fue uno de los gritos de batalla de la Revolución Americana. Tenemos un sistema de pesos y contrapesos para separar la función legislativa de imponer tributos y promulgar gastos, de la función ejecutiva de recaudar impuestos y administrar los programas de gasto, y de la función judicial de mediar en los conflictos e interpretar las leyes.

En este punto el hombre de negocios - ya sea el individuo o empleado directa o indirectamente por los accionistas - empieza a ser simultáneamente legislador, ejecutivo y jurista. Debe decidir quién pagará el tributo, en qué medida y a qué fin, y debe gastar lo recaudado - todo ello guiado sólo por exhortaciones genéricas desde arriba para contener la inflación, mejorar el medio ambiente, luchar contra la pobreza, etc.

Toda la justificación que permite al ejecutivo corporativo ser elegido por los accionistas es que el ejecutivo es un agente que sirve a los intereses del principal. Desaparece esta justificación cuando el ejecutivo corporativo fija impuestos y gasta la recaudación con fines "sociales". Se transforma efectivamente en un empleado público, aunque siga actuando como empleado de una empresa privada. Basándose en un principio político, resulta intolerable que estos empleados públicos - en la medida que sus actos en nombre de la responsabilidad social sean reales y no pura fachada - sean elegidos como lo son en la actualidad. Si terminan 
siendo empleados públicos, deben ser elegidos mediante un proceso político. Si van a fijar impuestos y gastar para fomentar objetivos "sociales", entonces debe ponerse en funcionamiento la maquinaria política para evaluar los impuestos y determinar a través de un proceso político los objetivos a cumplir.

Esta es la razón fundamental por la cual la doctrina de la "responsabilidad social” implica la aceptación del punto de vista socialista de que son los mecanismos políticos, no los de mercado, los apropiados para determinar la asignación de los recursos escasos a usos alternativos.

Basándose en las consecuencias, ¿podría el ejecutivo corporativo desembarazarse de las supuestas "responsabilidades sociales"? Por un lado, supongan que pudiera evitar gastar el dinero de los accionistas o de los clientes o de los empleados. ¿Cómo podría saber cómo gastarlo? Se le dice que debe contribuir a luchar contra la inflación. ¿Cómo puede saber qué hacer para lograrlo? Supuestamente, él es un experto en conducir un negocio - producir un producto, o venderlo, o financiarlo. Pero él no puede saber si su elección lo transformará en un experto en la lucha anti-inflacionaria. Si decide bajar el precio del producto, ¿̇reducirá las presiones inflacionarias? O por el contrario, al dejar más poder adquisitivo en manos de sus clientes, ¿̇no hará, simplemente, más que desviarlo hacia otros bienes? O, al obligarlo a producir menos a causa del precio más bajo, ¿no contribuirá a la escasez? Y si pudiera responder a estas preguntas, ¿qué costo se justifica imponer a sus accionistas, a sus consumidores y empleados para este objetivo social? ¿En qué proporción deben participar él y los demás?

Y, quiéralo o no, ¿̇puede librarse de gastar el dinero de sus accionistas, de sus clientes o empleados? ¿No terminarán echándolo los accionistas? (ya sean los actuales o los que se queden con la empresa cuando sus decisiones en nombre de la responsabilidad social hayan reducido los beneficios de la corporación o el precio de sus acciones.) Sus clientes y empleados pueden desertar a favor de otros productores y empleadores con menos escrúpulos a la hora de ejercer sus responsabilidades sociales. Este aspecto de la "responsabilidad social" se pone de relieve cuando la doctrina se utiliza para justificar la moderación salarial de los sindicatos. El conflicto de intereses se pone al desnudo y en forma clara si a los sindicalistas les piden que subordinen el interés de sus asociados a algún fin general. Si tratan de hacerles cumplir demandas moderadas, es posible que la consecuencia sea una huelga salvaje, una revuelta entre los miembros y la aparición de una fuerte competencia por sus puestos de trabajo. Tenemos entonces el fenómeno irónico - al menos en Estados Unidos - de sindicalistas que han planteado objeciones a las 
interferencias del Gobierno en el mercado de una forma mucho más consistente y corajuda que los líderes empresarios.

La dificultad de ejercer una "responsabilidad social", por supuesto, ilustra la gran virtud de la empresa competitiva privada - que obliga a la gente a ser responsable por sus actos y les hace difícil "explotar" a otros con propósitos ya sean egoístas o no. Pueden hacer el bien - pero solamente a su propio costo.

Muchos lectores que siguieron el argumento hasta aquí pueden intentar objetar que está bien decir que el Gobierno es el que tiene la responsabilidad de fijar impuestos y los gastos en objetivos "sociales" tales como el control de la contaminación o el entrenamiento de gente desempleada, pero que los problemas son demasiado apremiantes como para esperar el lento desarrollo de los procesos políticos, y que la responsabilidad social de los empresarios constituye una forma más rápida y segura de resolver los problemas urgentes existentes.

Dejando aparte una cuestión de hecho - comparto el escepticismo de Adam Smith sobre los beneficios que pueden esperarse de "los que influyen sobre el comercio con un fin público" - el argumento debe ser rechazado en base a una cuestión de principios. Equivale a afirmar que los que están a favor de los impuestos y el gasto en cuestión fracasaron en convencer a una mayoría de sus conciudadanos para que tengan una mentalidad similar y que están buscando alcanzar por medio de procedimientos anti-democráticos lo que no pueden hacer por medio de procedimientos democráticos. En una sociedad libre, es inaceptable que la gente "mala" haga "mal”, especialmente porque el bien de uno es el mal de otro.

Para simplificar, me he concentrado en el caso especial del ejecutivo corporativo, excepto para realizar una breve digresión sobre los sindicatos. Pero exactamente el mismo argumento se aplica al nuevo fenómeno de invocar a los accionistas para que exijan a las sociedades responsabilidad social (como el caso reciente de la cruzada por G.M., por ejemplo). La mayoría de las veces, lo que está implícito es que algunos accionistas están tratando que otros accionistas (o clientes o empleados) contribuyan en contra de su voluntad a causas "sociales" respaldadas por activistas. Si tienen éxito, estarán de nuevo imponiendo impuestos y gastando lo recaudado.

La situación del propietario individual es algo distinta. Si actúa para reducir los ingresos de su empresa a fin de ejercer su "responsabilidad social”, está gastando de su propio peculio y no del de los demás. Si desea gastar su plata de esa forma, está bien y no veo objeciones para que actúe de esa manera. En ese proceso 
también podrá terminar imponiendo costos a sus empleados o consumidores. Empero, como es mucho menos probable que él tenga poder monopolístico como una gran corporación o un sindicato, estos efectos colaterales serán de menor entidad.

Naturalmente, en la práctica la doctrina de la responsabilidad social es un manto que encubre otros motivos justificados por razones distintas a las expuestas. Por ejemplo, puede ser de interés de largo plazo que una corporación que emplea a muchos trabajadores de una pequeña comunidad que asigne recursos para facilitar comodidades a esa comunidad, o colaborar en mejorar su gobierno. Esto puede ayudar a atraer nuevos empleados habilidosos, a reducir la nómina salarial o a disminuir las pérdidas por hurto y sabotaje, u otras consecuencias valiosas. $\mathrm{O}$ también puede ser que con las leyes acerca de la deducibilidad de contribuciones caritativas de la corporación los accionistas contribuyan más a obras de caridad - porque de esa forma contribuyen en un monto que de no ser el caso hubieran debido pagar como impuestos corporativos.

En todos estos casos y otros similares, hay una gran tentación a racionalizar estas acciones como un ejercicio de "responsabilidad social”. Dentro del presente clima de opinión, con su animadversión al "capitalismo”, a los "beneficios”, a la "corporación sin alma” y a otros conceptos similares, ésta es la forma que tiene una corporación de generar buena voluntad como un sub-producto de gastos que se justifican totalmente en su propio interés.

Sería inconsistente decirles a los ejecutivos corporativos que no hagan esta decoración hipócrita porque causa daño a los fundamentos de una sociedad libre. ¡Sería lo mismo que exigirles una "responsabilidad social”! Si nuestras instituciones y las actitudes del público hacen que resulte de su propio interés encubrir sus acciones de esta forma, no puedo convocar demasiada indignación como para denunciarlos. A la vez, expreso mi admiración por los propietarios o accionistas que se resisten a esta táctica como fraudulenta.

Censurable o no, usar el pretexto de la responsabilidad social, y todo lo que dicen sin sentido en su nombre empresarios influyentes y prestigiosos, causa daño a los fundamentos de una sociedad libre. Muchas veces me ha causado impresión la esquizofrenia de algunos empresarios. Son capaces de tener una visión muy penetrante y clara en cuestiones internas de sus empresas. Pero son increíblemente cortos de vista y atolondrados en temas que están fuera de sus negocios pero que afectan la posibilidad de supervivencia general de los negocios. Esta cortedad de miras tiene un ejemplo rutilante en los pedidos que hacen muchos empresarios para que se establezcan guías, controles o políticas de salarios, precios e ingresos. 
Nada podría destrozar más rápidamente a un sistema de mercados que un sistema centralmente controlado y efectivo gubernamental de precios y salarios.

Esta cortedad de vista también se pone de ejemplo en los discursos de los empresarios sobre la responsabilidad social. Éstos les pueden dar algo de prestigio a corto plazo, pero contribuyen a la visión ya prevaleciente de que tratar de maximizar los beneficios es perverso e inmoral y que debe ser reprimido y controlado mediante fuerzas externas. Una vez adoptado este punto de vista, las fuerzas externas que repriman los mercados no serán las conciencias sociales, por más que estén muy desarrolladas, de los ejecutivos que pontifican: será el puño de hierro de los burócratas del Gobierno. Para mí, en estas cuestiones de controles de precios y salarios, los empresarios me parecen que revelan un impulso suicida.

El principio político que subyace al mecanismo de mercado es la unanimidad. En un mercado libre ideal que descanse en la propiedad privada, nadie puede obligar a otro, todas las cooperaciones son de carácter voluntario, y todas las partes que cooperan se benefician o, en caso contrario, no participan. No existen valores, ni responsabilidades "sociales” en ningún sentido que no sean valores compartidos y responsabilidades individuales. La sociedad es una colección de individuos y de los varios grupos que se forman de manera voluntaria.

El principio político que subyace al mecanismo político es la conformidad. El individuo debe estar sirviendo a un interés social más general - ya sea el fijado por una iglesia, un dictador, o una mayoría. El individuo puede llegar a votar y expresarse acerca de lo que debería hacerse, pero si es superado, debe prestar conformidad. A algunos les conviene exigir a otros que contribuyan a un fin social general, lo quieran o no.

Desafortunadamente, la unanimidad no siempre es factible. Hay aspectos en los que es inevitable prestar conformidad, de modo que no veo que aún se pueda evitar usar el mecanismo político.

Pero tomar en serio la doctrina de la "responsabilidad social" ampliaría el alcance del mecanismo político a todas las actividades humanas. Filosóficamente, no diferiría de la doctrina colectivista más explícita. Sólo se diferencia en hacer que se crea que los fines colectivistas pueden ser alcanzados sin los medios colectivistas. Por ello, en mi libro Capitalism and Freedom, la he llamado una "doctrina fundamentalmente subversiva" de una sociedad libre, y he dicho que en esta sociedad, "las empresas tienen una única responsabilidad social - emplear sus recursos y emprender actividades con el fin de aumentar sus beneficios, siempre que se 
desempeñen dentro de las reglas del juego, es decir, emprendan sus actividades en competencia abierta y libre sin engaños ni fraudes”.

\section{EVOLUCION DEL CONCEPTO DE RSE}

La anterior es la posición de Milton Friedman. No todos los economistas están encolumnados detrás de él (p. ej. Paul Samuelson, en 1971, argumentó que "lo mejor que podría hacer una gran corporación en estos días es comprometerse con una responsabilidad social”) ${ }^{3}$.

El concepto RSE fue introducido a mediados del siglo XX por Bowen ${ }^{4}$. Bowen comenzó diciendo que centenares de grandes empresas eran centros vitales de poder y decisión, y que las acciones de estas empresas afectaban la vida de los ciudadanos en varios puntos. Se preguntaba: ¿Qué responsabilidades hacia la sociedad se puede esperar que asuman los hombres de empresa en términos razonables? Definió a la RSE de la siguiente forma: "Son obligaciones de los hombres de empresa a seguir aquellas políticas, tomar aquellas decisiones, o seguir las líneas de acción que resulten deseables en función de objetivos y valores de nuestra sociedad" (p. 6). Bowen citaba una encuesta de una revista en la que los editores pensaban que la RSE o conciencia social de los empresarios significaba que los ejecutivos eran responsables por las consecuencias de sus acciones dentro de una esfera más amplia que la abarcada por sus cuentas de pérdidas y ganancias (Bowen, p. 44). Es interesante mencionar que 93.5\% de los encuestados estaba de acuerdo con este enunciado. Bowen afirmó que la RSE "no constituye una panacea pero que es una verdad importante que debe guiar a las empresas en el futuro".

En otro artículo clásico, en 1973 Keith Davis relacionó a la RSE con la consideración y respuesta de la empresa a cuestiones que van más allá de temas estrictamente económicos, técnicos o legales ${ }^{5}$. Es la obligación de una empresa de evaluar en su proceso de decisión los efectos de sus decisiones sobre el sistema social externo de modo de lograr beneficios sociales además de las ganancias económicas tradicionales buscadas. Lo cual significa que la responsabilidad social comienza cuando termina el derecho. Una empresa no actuaría en forma socialmente responsable si meramente se atuviera a lo que requiere el derecho, porque

\footnotetext{
${ }^{3}$ Paul A. Samuelson, Love that Corporation, Mountain Bell Magazine, Spring, 1971.

${ }^{4}$ Howard R. Bowen, Social Responsibilities of the Businessman, 1953. New York: Harper \& Row.

${ }^{5}$ Keith Davis, The Case for and against Business Assumption of Social Responsibilities, The Academy of Management Journal, Vol. 16, No. 2 (Jun., 1973), pp. 312-322.
} 
esto es lo que todo buen ciudadano haría. Una empresa que maximiza beneficios bajo las reglas de la economía clásica haría otro tanto. La responsabilidad social implica dar un paso más: asumir una obligación social más allá de lo requerido por el derecho.

Los argumentos reseñados por Davis son los siguientes:

A favor de la RSE: Intereses propios de largo plazo. Éste es el argumento principal. La sociedad, se supone, espera que las empresas cumplan una serie de objetivos sociales, y sus beneficios de largo plazo dependen de cumplir con estos objetivos. Está claro que estos objetivos no son de carácter altruista (son más bien objetivos estratégicos) aunque contribuyan a objetivos sociales. La empresa más “sensible” a las necesidades de su comunidad tendrá, de resultas, una mejor comunidad para realizar sus negocios. Será más fácil reclutar trabajadores, y éstos serán de mejor calidad. Bajarán el ausentismo y la rotación. En consecuencia, disminuirá el crimen y será necesario gastar menos en proteger la propiedad, con lo cual deberán ser pagados menos impuestos para sostener a las fuerzas de seguridad. En resumen, una mejor sociedad produce un mejor clima de negocios. Pero si se lo analiza más de cerca, no es más que un argumento sofisticado de maximización de beneficios a largo plazo. Puede sonar extraño sugerir que invertir en programas sociales tenga como resultado normal mayores beneficios, pero éste es el resultado de operar dentro de una mejor comunidad y una mejor sociedad a consecuencia de estos programas. Los verdaderos ahorros de reducción de costos a largo plazo dependen de lograr cumplir con estos bienes sociales; luego, la empresa que no realiza una contribución (tal vez porque el gobierno está ausente) tendrá menos beneficios en el futuro.

Imagen Pública Esta idea está vinculada con la anterior. Todas las empresas tratan de lograr una mejor imagen pública para tener mejores clientes, empleados, y otros beneficios. Esta conducta es tradicional dentro de los negocios, de modo que es fácil extender este concepto de imagen pública para cumplir con varios otros bienes sociales.

Viabilidad Esta idea, a diferencia de la imagen pública, se aplica a todo el sistema de empresas. Se dice que la institución empresarial existe sólo porque brinda servicios valiosos a la sociedad. Dentro de un argumento que tiene una connotación claramente socialista, la sociedad le "otorga" a la empresa un "privilegio" para existir, que podría ser enmendado o revocado si la empresa no cumple con las expectativas de la sociedad. Davis llama a ésta la Ley de Hierro de la Responsabilidad, o sea, "a largo plazo, los que no usen el poder de tal forma que la sociedad 
los considere responsables, lo perderán”. El largo plazo puede significar décadas o siglos, pero "la historia parece confirmar que la sociedad al fin de cuentas actúa para reducir el poder de los que no lo usaron de modo responsable". Davis añade que ésta no es una afirmación normativa, sino positiva: "es lo que sucederá con empresarios que no tengan una responsabilidad social aproximadamente igual a su poder social”. Esto significa que la doctrina económica clásica de ausencia de responsabilidad excepto para con la ley pierde mucho de su sentido, porque si se continúa en esa senda se producirá una pérdida sustancial de poder empresarial. La solución de este conflicto surge al reconocer que la responsabilidad social empresarial, basada en obligaciones y responsabilidades éticas, es obligatoria. Autores como Lantos sostienen como Milton Friedman que la RSE altruista no tiene sentido en las empresas ${ }^{6}$, y piensan que "en toda organización la ética (es decir, evitar causar daños a la sociedad) es una consideración obligatoria, que en las empresas que cotizan en bolsa la RSE altruista es ilegítima (hacer obras buenas a expensas de los accionistas), y que las empresas deberían limitar su filantropía a la RSE estratégica (hacer buenas obras que también sean positivas para los negocios)”. Lantos sostiene que la RSE ética es obligatoria en toda organización (esto es, evitar causar daños a la sociedad), y que la RSE altruista (hacer obras buenas a expensas de los accionistas) no es legítima en una sociedad por acciones, y que las empresas deberían limitar su filantropía a la RSE estratégica (hacer buenas obras que también sean buenas para la empresa).

Evitar la Regulación del Gobierno Si un empresario, adoptando una conducta "socialmente responsable", logra evitar que el Gobierno imponga nuevas restricciones a su accionar, lo hará a fin de preservar la descentralización de las decisiones. En efecto, de este modo evita una regulación que en general significa un costo para la empresa. Nuevamente, en este caso la RSE aparece como un instrumento para la libertad de acción empresaria.

Normas Socioculturales El empresario se desempeña bajo idénticas restricciones culturales que otras personas de la sociedad. Ahora bien, estas normas son tan reales como las restricciones tecnológicas, legales y de mercado que operan sobre la empresa. A medida que cambien estas normas, la conducta del empresario irá cambiando. Supóngase ahora que estas normas van evolucionando hacia normas de responsabilidad social. Las decisiones empresariales, aunque no estén plenamente determinadas por estas normas, irán cambiando hacia un patrón que refleje algún sentido de responsabilidad social. En otros términos, se conseguirán beneficios dentro de un conjunto determinado de normas sociales. Davis menciona

\footnotetext{
${ }^{6}$ Geoffrey P. Lantos, The Boundaries of Strategic Corporate Social Responsibility, June 2001.
} 
aquí que los empresarios suelen tener objetivos múltiples, por los cuales persigue "más que una satisfacción económica". Por ejemplo, mediante objetivos con un orden lexicográfico ${ }^{7}$. De esta forma, puede integrarse el objetivo de maximizar beneficios con otras normas de conducta.

Interés de los Accionistas Henry C. Wallich ha sostenido que la responsabilidad social resulta de interés de los accionistas en algunos casos, en sentido económico estricto. Mediante procedimientos analíticos, demostró que la diversificación de la cartera de los propietarios altera en forma radical el interés del accionista. Las actividades corporativas que no sean interesantes para un accionista de una sola firma pueden ser valiosas para un accionista diversificado, p. ej. el entrenamiento de empleados de baja capacidad; aunque el empleado se traslade a otra empresa, el inversor no pierde los beneficios conseguidos con su entrenamiento ${ }^{8}$.

"Probemos con las Empresas" Este argumento se vuelca hacia las empresas como institución, al constatar que otras instituciones que han sido creadas o diseñadas en el pasado han fracasado en manejar los problemas sociales. El argumento funciona algo así como: “¿Qué nos queda por probar? ¡Ya hemos probado con todos los demás!” o “¡No podría funcionar peor que lo existente!” Estos comentarios son exagerados y no demasiado elogiosos para las empresas. Ello plantea una cuestión molesta: ¿ hemos funcionado mal con algunos problemas sociales precisamente porque no se usó la capacidad de las empresas para resolverlos?

Las Empresas tienen Recursos Un argumento usado a veces es que, como las empresas tienen recursos valiosos que podrían aplicarse a la solución de problemas sociales, la sociedad podría emplearlos. Friedman ha señalado que esto equivale a admitir un rol de fijar impuestos y subsidios y de gastos que cabe al Congreso más que al Ejecutivo. Se agrega además que la actividad empresarial es conocida por su capacidad de innovación. Este argumento presenta problemas por las razones expuestas.

\footnotetext{
${ }^{7} \mathrm{El} \mathrm{nombre} \mathrm{proviene} \mathrm{de} \mathrm{la} \mathrm{forma} \mathrm{en} \mathrm{que} \mathrm{se} \mathrm{organiza} \mathrm{un} \mathrm{diccionario,} \mathrm{ya} \mathrm{que,} \mathrm{en} \mathrm{tal} \mathrm{caso,} \mathrm{se} \mathrm{le} \mathrm{da}$ prioridad al ordenamiento de los objetivos en forma análoga al ordenamiento de las palabras por letras en un diccionario. Por ejemplo, un empresario puede buscar una cierta tasa de rentabilidad sobre sus activos, pero si la logra con varias decisiones alternativas, decidirá entre ellas guiándose por un objetivo de responsabilidad social (p.ej., evitar la contaminación).

${ }^{8}$ H.V. Wallich \& J. J. McGowan, 1970, Stockholder interest and the corporation's role in social policy. In W. J. Baumol et al. (Ed.), A New Rationale for Corporate Social Policy: 39-59. New York: Committee for Economic Development, 1970.
} 
Los Problemas pueden transformarse en Beneficios No siempre sucede así, pero en algunos casos hay actividades que tienen problemas que pueden manejarse en forma rentable por medio de conceptos económicos. En algunas industrias del ramo de la petroquímica se halló que se puede reciclar basura con beneficio. También, imagínese a una empresa minera que está explotando cierto yacimiento de fosfato y descubre que puede convertir terrenos próximos a los lagos en mejores terrenos, con lo que obtiene una ganancia.

Mejor Prevenir que Curar Para terminar, Davis señala que si las empresas se atrasan en responder a los problemas sociales, se encontrarán permanentemente ocupadas en apagar "incendios sociales”, de modo que no podrán cumplir con su misión primaria de producir bienes y servicios. Como estos problemas sociales tarde o temprano deberán ser encarados, resulta más económico enfrentarlos ahora antes de que se transformen en explosiones mayores, lo que insumiría la mayor parte del tiempo de la administración. Detrás de este argumento vuelve a aparecer el de optimización a largo plazo.

Como se ha visto, los únicos argumentos que respaldan la asunción de responsabilidades sociales por parte de una empresa son, o bien su maximización de beneficios a largo plazo, o bien el argumento de diversificación del riesgo. Pasemos ahora a los argumentos contrapuestos.

Maximización de Beneficios Esta es la posición de Friedman, según la cual la función de una empresa es económica, y los valores económicos constituyen el único criterio que debe usarse para medir el éxito. El gerente es el agente de sus accionistas, y todas sus decisiones están controladas por su deseo de maximizar los beneficios de su principal. Es la misma posición de Lantos para empresas que cotizan en bolsa. Como se vio, si el ejecutivo usa recursos con fines de responsabilidad social, está gravando mediante impuestos a los accionistas, y luego decide, por afuera del sistema político - que es donde los impuestos deben ser asignados - cómo gastar los ingresos. Esta es una doctrina incompatible con un sistema de mercados.

Costos de la Participación Social Es cierto que, en general, las empresas disponen de recursos económicos sustanciales, que deben ser administrados sabiamente porque, en caso contrario, se produce su dilapidación - salvo que sean auto-renovables. Si bien las empresas pueden invertir recursos en obligaciones sociales, no podrá tratarse de montos importantes a menos que sean renovados durante el período de compromiso. Davis menciona el caso de fundiciones de metal marginales que no pudieron enfrentar el costo del nuevo equipamiento contra 
la contaminación, y que debieron cerrar sus puertas en forma permanente. Algo semejante sucedió con las fábricas químicas.

Carencia de Habilidades Sociales Muchos empresarios carecen de las percepciones y habilidades para cumplir con la tarea. No se sienten "en casa" realizando tareas sociales. Un analista señala: "Ver a gente sofisticada yendo a arrodillarse ante las empresas rogando que tengan un tipo de conciencia y de sensibilidad moral que pocas veces se encuentra en la gente produce risa”.

Dilución del Objetivo Primario de la Empresa En la práctica ésta es la primera objeción con un nuevo ropaje. Involucrarse en objetivos sociales diluye en general el énfasis sobre la productividad económica, divide los intereses de sus líderes, y debilita a la empresa dentro del mercado, lo que tiene como consecuencia que tendrá un mal desempeño tanto en el aspecto económico como social. La sociedad tendrá una menor productividad y se confundirá el papel de la institución de la empresa en la sociedad. El fracaso en las áreas económica y social empeorará la imagen pública de la empresa. En realidad, es probable que muchos de los problemas que la gente asignaría a las empresas no tengan solución real, lo que hará de las empresas el chivo expiatorio del "intercambio social”.

Problemas de Balance de Pagos Éste es un problema pocas veces apreciado por la asignación de RSE a las empresas. Los programas sociales implican aumentos de costos, que deben ser recuperados; en general, lo serán aumentando el precio del producto. Si las "actividades sociales" diluyen la capacidad empresaria en materia de productividad, esta eficiencia más reducida se traducirá en costos de producción más altos. Si estas empresas compiten en mercados internacionales con otras firmas - que no tienen una RSE que aumenta los costos de sus productos - las empresas locales tendrán una desventaja competitiva. Una peor situación del balance de pagos puede conducir a problemas monetarios internacionales y a pérdida de puestos de trabajo al país que impuso RSE a sus empresas.

En 1972 hubo un debate importante sobre RSE, bajo el patrocinio del American Enterprise Institute. Manne y Wallich resumieron el debate en un libro en el que ofrecieron su propia definición de RSE ${ }^{9}$ : Para que un gasto comercial o una actividad califique como una acción corporativa socialmente responsable, debe ser tal que el ingreso marginal para la corporación sea inferior al ingreso marginal resultante de gastos alternativos, debe ser totalmente voluntario, y debe constituir un

\footnotetext{
${ }^{9}$ H.G. Manne and H.C. Wallich (1972). The modern corporation and social responsibility. Washington, DC: American Enterprise Institute for Public Policy Research.
} 
gasto corporativo más que una conducta de generosidad individual. Manne agregó que aún en tales casos, en la práctica resulta sumamente difícil, por no decir imposible, distinguir entre un gasto puramente comercial y otro que se dice haber sido hecho para bien del público. Puso énfasis en que los gastos empresarios pueden tener diversos motivos, por lo cual éste no es un criterio útil para juzgar la responsabilidad social. El factor de voluntad ha sido puesto en primer plano por distintas definiciones modernas de la RSE, pero ello también es harto difícil de juzgar: es imposible distinguir entre lo "puramente voluntario" y lo que responde a normas sociales ${ }^{10}$. Wallich definió a la RSE en términos amplios, como una condición en la cual la corporación constituye en cierta medida un agente libre. Si los objetivos sociales le son impuestos por el derecho, la corporación no ejerce ninguna RSE si los lleva a cabo. En esto hay coincidencia con Davis: la responsabilidad social comienza cuando termina el derecho. Wallich dijo que hay circunstancias en las que puede defenderse la existencia de RSE, pero se mostró a favor de que hubiera instrucciones explícitas de los accionistas a la corporación a fin de que ésta fuera responsable para con los intereses de los accionistas (pp. 56-62).

A fines de los 1970's, Carroll publicó un artículo en el que propuso una definición en cuatro partes de RSE ${ }^{11}$. Dijo que en primer término la empresa tiene una responsabilidad económica: “... tiene la responsabilidad de producir bienes y servicios requeridos por la sociedad y venderlos a beneficio. Las demás funciones de la empresa son predicadas usando como base este supuesto fundamental. Es decir, así funciona un sistema capitalista usando al beneficio como herramienta de incentivo y de premio. La sociedad también espera que la empresa obedezca al derecho, es decir las reglas básicas del juego mediante las cuales funciona la empresa. Más allá del derecho, cabe mencionar a la responsabilidad ética (conducta y prácticas que van más allá de lo exigido por el derecho).” En 1991 Carroll elaboraría algo más esta idea ${ }^{12}$. Finalmente, están las responsabilidades discrecionales, roles voluntarios asumidos por las empresas para los cuales la sociedad no facilita una expectativa clara, como lo hace en materia de responsabilidad ética.

En los 1980’s no hubo muchas más definiciones de RSE, aunque sí intentos de medición y de investigación, y marcos teóricos alternativos. Por fin, en los 1990’s hubo una transición a temas como la teoría de las partes interesadas en la

\footnotetext{
${ }^{10}$ Ver Jon Elster, 1989, Social Norms and Economic Theory, Journal of Economic Perspectives, 3 (4).

${ }^{11}$ Archie B. Carroll, A three-dimensional conceptual model of corporate performance, Academy of Management. The Academy of Management Review (pre-1986); Oct 1979.

${ }^{12}$ Archie B. Carroll, The Pyramid of Corporate Social Responsibility: Toward the Moral Management of Organizational Stakeholders, Business Horizons, July-August 1991.
} 


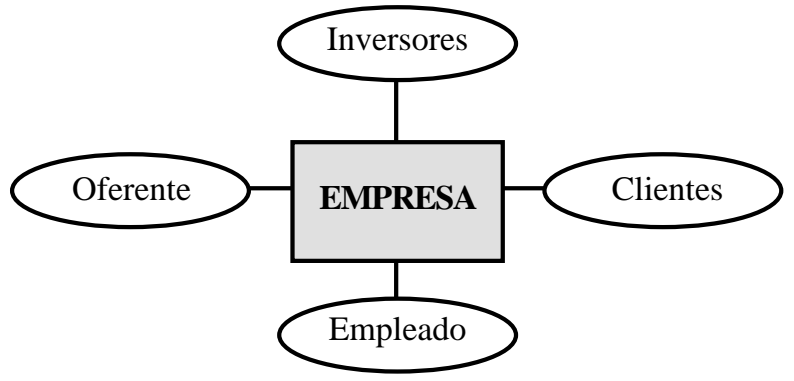

Modelo Insumo-Producto
de la Corporación

empresa (stakeholder theory), la teoría de la ética comercial y la ciudadanía corporativa. Tomaré como referencia un documento de Donaldson and Preston ${ }^{13}$, del cual reproduzco dos figuras que servirán al efecto de esta discusión. La primera figura adjunta representa el modelo tradicional de la corporación, donde la empresa aparece como caja negra que transforma los insumos en productos destinados a beneficiar a los clientes. Por supuesto, cada proveedor de insumos (inversor o empleado) de la empresa espera recibir una compensación adecuada, pero en el caso competitivo sólo recibe su beneficio "normal” (o costo de oportunidad). Naturalmente, los inversores individuales que tengan ventajas particulares (como una localización más ventajosa, o una habilidad específica) recibirán "rentas”, pero como poseedores de esos recursos escasos sólo obtendrán beneficios normales. A raíz de la competencia, la mayoría de los beneficios se trasladarán a los consumidores. Los flujos van desde los inversores, oferentes y empleados a la empresa, y de ésta a los clientes.

En el modelo del stakeholder se sostiene que todas las personas o grupos que tengan intereses legítimos en participar en una empresa así lo harán para beneficiarse, y que no hay prima facie prioridad de un conjunto de interesados y beneficios sobre otros. Luego, los flujos entre la empresa y cualquiera de las partes interesadas van en ambas direcciones. La obra de Freeman puede ser considerada como uno de los mayores aportes a esta literatura ${ }^{14}$. En su tratamiento original,

\footnotetext{
${ }^{13}$ Thomas Donaldson and Lee E. Preston, The Stakeholder Theory of the Corporation: Concepts, Evidence, and Implications, The Academy of Management Review, Vol. 20, No. 1 (Jan., 1995), pp. 65-91.

${ }^{14}$ R. Edward Freeman and John McVea, A Stakeholder Approach to Strategic Management, Darden Business School Working Paper No. 01-02, 2001; R. Edward Freeman, Strategic Management: A
} 
aseguraba que los eventos daban lugar a un rol descriptivo de la teoría: así como la separación entre propietario, gerente y empleado requería reformular el concepto de control y de propiedad privada como lo hicieron Berle y Means ${ }^{15}$, el surgimiento de numerosos grupos de interesados y de nuevas cuestiones estratégicas requiere volver a pensar el esquema tradicional de la empresa (1984, p. 24).

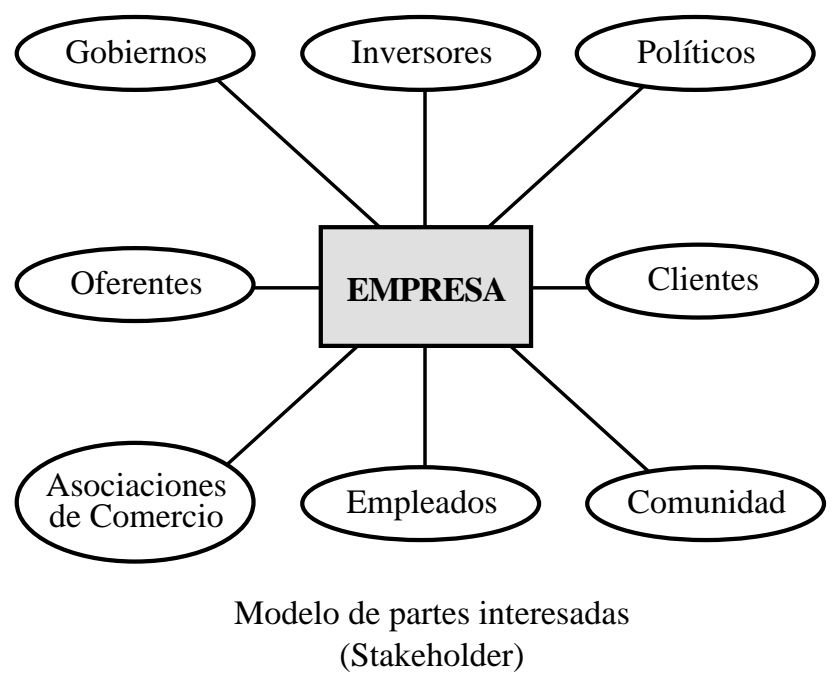

Al mismo tiempo, sostuvo una teoría de la base instrumental: Debe explorarse la lógica del concepto en términos prácticos, o sea en términos de cómo pueden las organizaciones tener éxito dentro del entorno comercial presente y futuro (1984, p. 25). Pero, posteriormente sostuvo la teoría del stakeholder sobre bases normativas, a saber la capacidad de satisfacer los derechos morales de los individuos ${ }^{16}$. Con Evan afirmó que la teoría de la empresa debe ser re-conceptualizada siguiendo líneas esencialmente kantianas, lo que significaría que cada grupo interesado tiene derecho a ser tratado como fin en sí mismo, no como un medio para conseguir otro fin, "y por consiguiente debe participar en la futura dirección de la empresa de la que es parte interesada.”

\footnotetext{
Stakeholder Approach (Pitman, 1984).

${ }^{15}$ Adolf A. Berle and Gardiner C. Means, The modern corporation and private property, Transaction Publishers, 1932.

${ }^{16}$ W.M. Evan \& R.E. Freeman, 1988. A stakeholder theory of the modern corporation: Kantian capitalism. In T. Beauchamp \& N. Bowie (Eds.), Ethical theory and business: 75-93. Englewood Cliffs, NJ: Prentice Hall.
} 
La teoría del stakeholder a veces se justifica en la literatura recurriendo a preceptos descriptivos, instrumentales, o normativos. Los primeros tratan de exhibir cómo los conceptos teóricos se corresponden con los datos observados reales. Justificar en sentido instrumental apunta a mostrar evidencia de la conexión entre la administración de las partes interesadas y la performance corporativa. Las justificaciones normativas apelan a conceptos como los "derechos" de individuos o grupos, el "contrato social”, o el utilitarismo. Donaldson y Preston sostienen que el núcleo central de la teoría es normativo. Señalan que una forma de elaborar un fundamento normativo de esta teoría es compararla con su competidor principal, el modelo de control administrativo en manos de los accionistas. Pejovich y Furubotn han observado que en la corporación moderna (no así en la empresa dirigida por su propietario) los derechos de los accionistas están "atenuados” por la dispersión de la propiedad y los elevados costos de agencia ${ }^{17}$; y que es el sistema económico, no el legal, el responsable de atenuar los derechos de los propietarios. En base a que una teoría de la propiedad constituye un fundamento de la teoría del stakeholder, Dondaldson y Preston tratan a la filosofía de la propiedad como una corriente que, en el siglo XX, se contrapuso a la doctrina que considera a la propiedad privada como una concepción que consagra en forma exclusiva los intereses de los propietarios (p.ej. Coase) ${ }^{18}$.

A lo cual cabe agregar que propiedad privada y control colectivo no son alternativas todo-o-nada. En toda sociedad moderna, hay recursos asignados mediante reglas de propiedad común (calles, plazas), otros mediante reglas de propiedad colectiva (bases militares y piezas de artillería) y otros son de propiedad privada (cepillos de dientes, bicicletas). Y existen variantes acerca del grado de libertad que un propietario individual puede tener sobre los recursos que tiene asignados. Y obviamente, la libertad de un propietario está limitada por reglas de conducta de fondo: no puedo usar mi revólver para matar a otro. No se trata estrictamente de reglas de propiedad; un ejemplo más cercano son restricciones como la zonificación, que involucran imponer una decisión colectiva sobre ciertos aspectos del uso de un recurso determinado. El propietario de un edificio en un distrito histórico podrá usarlo, p.ej., como hogar, hotel, o negocio, pero no podrá demolerlo o reemplazarlo por un rascacielos. En este caso, puede decirse que el edificio histórico es propiedad privada; pero si hubiera muchas otras áreas de decisión acerca de su

\footnotetext{
${ }^{17}$ Erik G. Furubotn and Svetozar Pejovich, Property Rights and Economic Theory: A Survey of Recent Literature, Journal of Economic Literature, 10(4), December 1972.

${ }^{18}$ Ronald H. Coase, The problem of social cost, The Journal of Law and Economics, Volume III, October 1960 Ronald H. Coase, The problem of social cost, The Journal of Law and Economics, Volume III, October 1960
} 
uso controladas por organismos públicos, nos sentiremos más inclinados a decir que está sujeto a una regla de propiedad colectiva (donde el "propietario" funciona como un administrador de las decisiones de la sociedad $)^{19}$.

Hace más de cincuenta años, Coase reprendió a los economistas por adherir a un concepto demasiado simplista de la propiedad: "Podemos hablar de una persona que es propietaria de un terreno... pero lo que el propietario posee en realidad es el derecho a llevar a cabo un conjunto circunscripto de acciones. Los derechos no son ilimitados... Ello sería válido en cualquier sistema jurídico. Un sistema en el que los derechos de los individuos fueran ilimitados sería uno en el que los derechos no podrían ser transferidos." Pejovich y Furubotn enfatizan que los derechos de propiedad son relaciones entre individuos, y que es erróneo separar a los seres humanos de los derechos de propiedad. Lo llamativo es que la literatura sobre propiedad privada no asigna derechos ilimitados a los propietarios y, por ende, no sustenta el enfoque de que la responsabilidad de los administradores es actuar sólo como agentes de los accionistas, à la Friedman.

Diversos analistas de los derechos de propiedad rechazan la noción de que pueda existir una única teoría de la justicia distributiva aplicable en forma universal. Becker ${ }^{20}$, cuyo análisis dio lugar a un enfoque pluralista, permitió que más de un único principio fundamental desempeñe algún rol. Todos los elementos críticos que están detrás de las teorías clásicas de la justicia distributiva están presentes entre los interesados de una corporación. Por ejemplo, el “interés” de los empleados a largo plazo que han trabajado para construir y sostener una operación comercial exitosa está basado esencialmente en el esfuerzo. El interés de gente que vive en la comunidad circundante puede estar basado, p.ej., en el aire puro o en mantener la infraestructura civil. El interés de los clientes está basado en su satisfacción y en las protecciones ofrecidas implícitamente en la oferta de mercado. Y así sucesivamente. Donaldson y Preston concluyen luego que los principios normativos por detrás de la teoría pluralista de los derechos de propiedad también facilitan un fundamento para la teoría de las partes interesadas.

Cuestiones de legitimidad Freeman (1984) había identificado con excesiva amplitud a los interesados, como "todos los que influyen o pueden ser influidos por la empresa”. Ello abre la perspectiva de incorporar a interesados que formen parte del entorno - pero no tengan interés alguno en la propia empresa. Los dos tipos de intereses que han sido introducidos de modo más frecuente son (a) los

\footnotetext{
${ }^{19}$ Stanford Encyclopedia of Philosophy, Property and Ownership First published Mon Sep 6, 2004.

${ }^{20}$ L. C. Becker, 1992. Property. In L. D. Becker \& C. B. Becker (Eds.), Encyclopedia of ethics, vol. 2: 1023-1027. New York: Garland.
} 
competidores; y (b) los medios de comunicación. Los competidores fueron introducidos como factores que "desempeñan una influencia sobre la autonomía de la administración” en el artículo de Dill - que ha sido citado como un precursor de la teoría de las partes interesadas ${ }^{21}$. En circunstancias normales, los competidores no buscan beneficios a través del éxito de la empresa; más bien al contrario, pueden llegar a perder toda vez que la empresa es rentable. Naturalmente, las empresas competitivas pueden asociarse en actividades comunes de colaboración (p.ej. mediante asociaciones comerciales), pero en tal caso los intereses compartidos (no competitivos) toman en cuenta la relación de parte interesada. Con respecto a los medios de comunicación, ya Freeman los había tenido en cuenta como partes interesadas, pero los eliminó en escritos posteriores. Donaldson y Preston señalan que resulta imprescindible distinguir entre "influyentes” y "partes interesadas". Hay quienes pueden estar en ambas categorías, como los grandes inversores, pero hay partes interesadas que no tienen influencia alguna (como los que buscan trabajo) y hay influyentes que, en principio, no son parte interesada (como los medios de comunicación).

Es contradictorio el papel de los administradores dentro de la teoría del stakeholder. Aoki, por ejemplo, reconoce que sólo los inversores y los empleados son partes interesadas significativas y aprecia que los administradores serían meramente "referees" entre estas dos partes ${ }^{22}$. No reconoce ni el papel esencial de los administradores identificando a las partes interesadas, ni el hecho de que constituyen, de por sí, una clase muy privilegiada de parte interesada dentro de la empresa. Entre los analistas académicos, cabe citar a Oliver Williamson que pone énfasis en que los administradores de una empresa son una de sus circunscripciones más poderosas y que es probable que practiquen una conducta oportunista y egoísta ${ }^{23}$.

Donaldson y Preston concluyen su reseña indicando que la teoría de las partes interesadas es, fundamentalmente, de carácter "administrativo", y que la teoría recomienda aplicar actitudes, estructuras, y prácticas que, todas ellas, constituyen una filosofía de administración de las partes interesadas. Pero el análisis del vínculo entre la administración de las partes interesadas y la performance de la corporación descansa, en última instancia, en argumentos normativos.

\footnotetext{
${ }^{21}$ W.R. Dill, 1958. Environment as an influence on managerial autonomy. Administrative Science Quarterly, 2: 409-443.

22 M. Aoki, The co-operative game theory of the firm, 1984, Clarendon Press (Oxford Oxfordshire and New York).

${ }^{23}$ Oliver Williamson, The economic institutions of capitalism. Firms, markets, relational contracting, Das Summa Summarum des Management, 1985, 2007, Kapitel I, 61-75.
} 


\section{DESCENTRALIZACION}

Los análisis de raíz marxista (y, en general, todos los críticos de la economía neoclásica moderna) ignoran en forma central un punto debatido en la llamada "controversia del socialismo", a saber que la información sobre preferencias y tecnologías en una economía está “dispersa”, o sea no está concentrada o compendiada en una sola mente o un único procesador abarcando todos los datos relevantes. Contra la ingenua creencia de algunos socialistas, ya Pareto y Barone habían destacado las virtudes de la descentralización en términos de la información de un sistema competitivo. Por ejemplo, Pareto y Barone pudieron demostrar cómo el funcionamiento óptimo de una economía centralmente planificada esencialmente imitaría a una economía de mercado ${ }^{24}$. Estos economistas tuvieron gran influencia en las discusiones tempranas de los sistemas económicos y en la rama de la disciplina conocida como "economía del bienestar" - es decir, el estudio de cómo los sistemas económicos pueden ser diseñados para promover el bienestar humano, y no sólo el estudio de los programas de bienestar de asistencia pública. Por ejemplo, Barone sostuvo que le parecía mucho más fácil, en principio, tener mercados para coordinar la economía a través de señales de precios que tener una burocracia centralizada que determinara todo. Esta idea le pareció atractiva a Friedrich Hayek, que incluyó en un libro titulado Planificación Económica Colectivista una traducción al inglés del artículo de Barone $(1908)^{25}$. De hecho, en aquellos días invertir numéricamente incluso una matriz muy pequeña podía llevar una semana de esfuerzos intensos de equipos humanos. Así que el problema del cálculo de un plan óptimo sería claramente inmanejable. Esto hizo que las economías de mercado parecieran preferibles porque parecían requerir un procesamiento mucho menos centralizado de la información. En efecto, un sistema de mercado puede funcionar como una especie de máquina de computación de "proceso en paralelo", tanto para el cálculo como para la puesta en marcha de una asignación óptima de bienes, servicios, recursos, mano de obra, etc. en la economía ${ }^{26}$. Naturalmente, la historia del análisis económico posterior mostraría

\footnotetext{
${ }^{24}$ Véase también A.P. Kirman (1987), Pareto as an Economist, in J. Eatwell, M. Milgate, and P. Newman (eds.), The New Palgrave Dictionary of Economics (London: Macmillan).

${ }^{25}$ Friedrich A. Hayek, comp., Collectivist Economic Planning: Critical Studies on the Possibilities of Socialism, George Routledge and Sons, Londres, 1935. En este volume Hayek incluyó el conocido ensayo de Ludwig von Mises, "Economic Calculation in the Socialist Commonwealth" (1920), trad. S. Adler.

${ }^{26}$ Esta idea del mercado como una máquina de computación en paralelo fue enfatizada por Oskar Lange, The Computer and the Market, 1967, in C. H. Feinstein, ed., Socialism, Capitalism and Economic Growth, Cambridge University Press.
} 
innumerables desarrollos que permiten enfocar estos problemas sobre bases más sólidas ${ }^{27}$.

La evolución de las economías socialistas (primero la soviética, luego los países de Europa del este, luego China y Vietnam) pondría en evidencia la importancia de este concepto, que puede considerarse como el más importante de la economía capitalista. Es inmediato que el capitalismo no requiere que la coordinación del mercado sea dominante. Esto no excluye la presencia de otros mecanismos de coordinación, como la intervención burocrática; sin embargo, una característica esencial del capitalismo es que el principal mecanismo de coordinación económica se produzca a través del mercado, a través de ajustes mutuos y descentralizados de la oferta, la demanda, de cantidades y precios. Como trae a cuento Janos Kornai, en un sistema capitalista constituyen partes esenciales el predominio de la propiedad privada y la coordinación dominante por medio de mercados ${ }^{28}$. La propiedad privada en el capitalismo no tiene por qué dominar absolutamente. En el capitalismo moderno, las organizaciones públicas y sin fines de lucro también pueden desempeñar un rol. Pero estas organizaciones no privadas no deben tener un papel dominante.

Redefiniendo en forma apropiada los beneficios de la empresa para contemplar también el largo plazo, una empresa puede ser vista como un instrumento para la maximización de beneficios, y por consiguiente, "debe” rendir cuentas a sus propietarios. En la teoría económica clásica y moderna, tal es el concepto que se tiene de la empresa. Imponerle una obligación distinta, ya sea social, política o de otro tipo, tiene el mismo efecto que un impuesto cobrado a sus propietarios. Si se desea que éste sea un rol a cumplir por las empresas, los tributos deberían ser definidos por la legislatura, de la misma forma que la asignación de los ingresos generados. Un punto no menor del argumento es el grado de conocimiento y coordinación de los empresarios para cumplir con las supuestas RSE. Descentralización de las decisiones y RSE son objetivos incompatibles entre sí. Veámoslo de la siguiente manera: si tuviera que asignarse un rol a las empresas dentro de un sistema económico, el único rol posible con interesados diversos es el de maximizar la riqueza de los accionistas a través de su actividad en el mercado. Cualquiera otra parte interesada (stakeholder) requeriría que dicha parte esté representada como accionista de la empresa.

\footnotetext{
${ }^{27}$ A modo de resumen, véase P. Hammond, “The Role of Information in Economics,” L’Informazione nell’ Economia e nel Diritto (Milán, 1990).

${ }^{28}$ Janos Kornai, What the Change of System From Socialism to Capitalism Does and Does Not Mean, Journal of Economic Perspectives-Volume 14, Number I-Winter 2000-Pages 27-42.
} 
Milton Friedman estaba, pues, en lo cierto al subrayar el carácter central que en la economía debe desempeñar una empresa. Además, subrayó enfáticamente la diferencia entre los análisis de tipo positivo y normativo, indicando que "la Economía es una ciencia positiva de generalizaciones aceptadas en forma preliminar sobre fenómenos económicos que pueden usarse para predecir las consecuencias de cambios en las circunstancias" ${ }^{29}$. De los enfoques alternativos, tal vez el más prometedor sea el de Henry C. Wallich. Sea como fuere, la tendencia indica que las empresas han comenzado a adoptar la RSE no sólo como resultado de presiones de los consumidores, los proveedores, la comunidad, las organizaciones de activistas, los inversionistas, etc.; la RSE es también una actividad estratégica adicional en la competencia comercial. La empresa cumple un papel importante en la vida de las personas no sólo como generadora de empleo y de riqueza, sino además como agente de desarrollo en las comunidades en las que está inserta. Las grandes empresas son conscientes de ello y aprovechan las expectativas que genera la RSE para obtener ventajas competitivas (ayudan ayudándose). La filantropía corporativa ha dejado de ser una actividad autónoma confiada a una fundación y cada vez más forma parte de las estrategias que contribuyen a realizar el objeto social de la empresa. Nuestra hipótesis es que, en tales casos, la RSE constituye una estrategia de maximización de lucro.

\section{ASPECTOS POSITIVOS Y NORMATIVOS Y CRITICA AL USO DEL CONCEPTO}

La literatura ofrece buena cantidad de definiciones no siempre concordantes del significado atribuido a la RSE. Pero ello no es óbice para quienes han estado a favor de un enfoque normativo para formular propuestas destinadas a influir sobre la opinión pública ${ }^{30}$. Según este enfoque, cambios recientes en la escena mundial y presiones de la opinión pública requieren que las empresas adopten nuevos roles y misiones más definidas, a saber lograr objetivos compartidos de políticas públicas y que el mundo se transforme en un lugar mejor para vivir. O sea, deberían abrazarse a la noción de “ciudadanos del mundo”. Deberían llevar a cabo su gestión en coordinación estrecha con diversas partes interesadas, a fin de lograr un objetivo común de desarrollo sustentable (del que se dice que tiene tres

\footnotetext{
${ }^{29}$ Milton Friedman, The Methodology of Positive Economics, sec. V ("Some Implications for Economic Issues”), (1953) University of Chicago Press

${ }^{30}$ David Henderson, The Case Against “Corporate Social Responsibility”, Policy, The Globalization Reader. 3rd ed. Ed Lechner, Frank and John Boli. Malden, MA: Blackwell Publishing, 2008. 202-207
} 
dimensiones, la económica, la ambiental, y la social). Las empresas deberían fijar sus objetivos, medir su performance, y ser independientemente auditadas, con respecto a los tres objetivos. No deberían concentrarse "estrechamente" en nociones como la rentabilidad o el valor para los accionistas.

El concepto de RSE hizo pie en el discurso público cotidiano. La doctrina de la RSE puede injertarse en una economía capitalista respetando o no su funcionamiento. Un ejemplo del primer caso: al aumentar los problemas asociados al cambio climático, se espera que en el futuro el sistema empresario desempeñe un rol más activo en la lucha mundial contra la contaminación. La organización intergubernamental IPCC puso énfasis en la adopción de mecanismos pro-mercado en la reducción de gases y ácidos contaminantes originados por la actividad humana (como el dióxido de carbono). No hay ningún obstáculo para que las empresas participen en forma activa de los mecanismos puestos en marcha, respetando los mecanismos de mercado usuales en una economía capitalista (por ejemplo, mediante el comercio de bonos de carbono o la compra-venta de externalidades). Según informan reputados analistas políticos, en nuestro país hay cuatro problemas que están en la "agenda de la población": inseguridad, desempleo, inflación y salarios ${ }^{31}$. No parecen problemas a ser resueltos en forma descentralizada por las empresas. Más aún, el análisis económico diría que han sido creados por las políticas gubernamentales.

A la inversa, la adopción de una doctrina de RSE incompatible con el funcionamiento de una economía capitalista podría significar consecuencias negativas.

Quienes sostienen la noción de RSE como objetivo a ser perseguido por la nación y el sistema económico suponen que los problemas enfrentados tienen soluciones conocidas y concordantes para todos los miembros de la sociedad. No es tal. Aún problemas relativamente "simples" como la elección ente modalidades y tecnologías de oferta energética plantea arduos problemas de cálculos de costos y beneficios, comparación de valores presentes y futuros mediante tasas de descuento, consideración de flujos inciertos de demanda, etc. que exigirían para su apropiada coordinación la fijación de parámetros centrales de una agencia que redujera así la incompatibilidad de soluciones. Aún si se deja de lado la existencia de problemas ambientales y sociales, resulta claro que el sistema de empresas no debería acometer la fijación de objetivos descentralizados inconmensurables con el beneficio. Hay quienes creen que las RSE deberían en tales casos provenir de grupos (ONGs, comentaristas, parlamentarios, etc.) a los cuales cabría escuchar.

\footnotetext{
${ }^{31}$ Sergio Berensztein, La etapa jacobina del kirchnerismo, Foco Económico, 26 de agosto de 2012.
} 
Estos grupos serán incapaces, en general, de formular propuestas coherentes, básicamente por dos problemas: 1) inadecuación de la información; 2) un problema de agregación de preferencias. Como menciona The Economist ${ }^{32}$, la RSE es el tributo que el capitalismo paga a la virtud. Obtener las ventajas del capitalismo requiere intervención pública de distintos tipos, en general una considerable intervención: impuestos, gasto público, y regulación de diversas áreas de la economía. También requiere que los ejecutivos corporativos sean responsables - pero a la gente indicada y de la manera correcta. La RSE no puede ser un sustituto de políticas sabias en estas áreas. Y hasta cierto punto, puede constituir un obstáculo. Para mejorar al capitalismo, primero es necesario entender cómo funciona. Pero lo que se ha escrito y dicho sobre RSE, en general, no cumple con este precepto.

La RSE suele conducir a adoptar un enfoque alarmista sobre el estado del entorno y el daño causado por la actividad económica, a la creencia de que deben tomarse decisiones fatídicas en nombre de la humanidad y el planeta, y a una visión distorsionada del sistema capitalista, de la globalización y de sus efectos. Al contrario de lo pregonado por este tipo de afirmaciones, la globalización no ha implicado “exclusión social”, ni puso al “margen” a países más pobres. Tampoco trajo "enormes" beneficios a las empresas multinacionales, ni aumentó su poder para influir sobre los eventos reduciendo el poder de los gobiernos. Por el contrario, los gobiernos siguen manteniendo su capacidad de acción, y en los años recientes las privatizaciones, la desregulación y la liberación del comercio a través de las fronteras y de los flujos de capital han contribuido a reducir el poder económico de las empresas haciendo que los mercados sean más abiertos y competitivos. El comercio mundial, en los 1990's, ha crecido tres veces a la velocidad del PIB. Esto implica que las economías nacionales están más vinculadas entre sí. Dice Ramón Tamames: "La globalización "per se” es buena. Históricamente, a ningún país le ha venido mal la globalización. Ahí tenemos el ejemplo de España, sin ir más lejos. La carrera española hacia la globalización comenzó en 1959 con el Plan de Estabilización. Siguió con el Acuerdo Preferencial con la Comunidad Europea en 1970, con la entrada en la Unión Europea en 1986, y en la Unión Monetaria y Económica en 1998. Los que están mal son los países que no se globalizan: Birmania, Irak... El mundo árabe, globalmente hablando, es una desgracia. No lo digo en tono peyorativo. No hay ningún país de la zona que esté al nivel de las posibilidades que se podían esperar de ellos. Quizá la única excepción sea Túnez.”33 ${ }^{34}$

\footnotetext{
32 The Good Company, Jan. 20th, 2005. http://www.economist.com/node/3555212?Story_ id $=3555212$

${ }^{33}$ Ramón Tamames, A ningún país le viene mal la globalización, Capital № 11; Agosto 2001.
} 
El problema de la RSE no es sólo que sea dudosa, sino que su implementación podría ser perjudicial. En los negocios la adopción de RSE implicará una mayor probabilidad de aumento de costos y de una peor performance. Si hay que tomar en cuenta una gama más amplia de objetivos y cuestiones, los ejecutivos deberán involucrarse en nuevos procesos engorrosos de consulta con partes interesadas externas a la empresa. Se requerirán nuevos sistemas de contabilidad, monitoreo y auditoría. Encima de todo, al adoptarse estándares ambientales y sociales los costos aumentarán, especialmente al insistirse en que las empresas competidoras, oferentes y contratistas usen los mismos estándares. Más aún, los incrementos de costos no serán acompañados por aumentos equiparables de los beneficios. Existe el riesgo de que los resultados de insistir en la así llamada "eco-eficiencia" no deparen los beneficios esperados, dejando a todos los habitantes en peor situación (un movimiento hacia una posición Pareto-inferior).

Cuando las empresas fracasan en discutir, o incluso hacen suyos, los argumentos y demandas de grupos activistas anti-empresariales, no hacen otra cosa que aceptar las ideas líderes del salvacionismo. Al igual que Henderson, veo con preocupación la actitud de muchos líderes empresarios y corporativos que ceden al espíritu de los tiempos, haciendo propios argumentos que, como menciona Friedman, terminan poniendo en jaque al propio sistema de empresas sobre el que está basado la economía capitalista.

\section{CONCLUSION}

Los riesgos de ceder a ideas como la RSE son muy altos para una economía capitalista: puede perderse el anclaje principal sobre el que está estructurada y el único objetivo que a mi juicio debería orientar la actividad económica. El Estado también debe cumplir su rol. Es tiempo de ver cara a cara la principal proposición de Adam Smith en una economía capitalista: "It is not from the benevolence of the butcher, the brewer, or the baker that we expect our dinner, but from their regard to their own interest. We address ourselves, not to their humanity but to their self-love, and never talk to them of our own necessities but of their advantages34.”

\footnotetext{
${ }^{34}$ Adam Smith, An Inquiry into the Nature and Causes of the Wealth of Nations, 1776. Book One, Chapter Two, Of the Principle which gives occasion to the Division of Labour.
} 


\section{REFERENCIAS BIBLIOGRAFICAS}

Frederik, W., (1978), From CSR1 to CSR2: The Maturing of Business-and-Society Thought, Univ. of Pittsburgh.

Friedman, M., (September 13, 1970), "The Social Responsibility of Business is to Increase its Profits”, The New York Times Magazine.

Samuelson, P. A., (1971), "Love that Corporation”, Mountain Bell Magazine, Spring.

Bowen, H. R., (1953), Social Responsibilities of the Businessman. New York: Harper \& Row.

Davis, K., (1973), “The Case for and against Business Assumption of Social Responsibilities”, The Academy of Management Journal, Vol. 16, (2), jun, pp. 312-322.

Lantos, G. P., (2001), “The boundaries of strategic corporate social responsibility”, Journal of Consumer Marketing, Vol. 18, Iss: 7, pp.595 - 632.

Wallich, H.V. and McGowan, J. J., (1970), Stockholder interest and the corporation's role in social policy. In W. J. Baumol et al. (Ed.), A New Rationale for Corporate Social Policy: pp.39-59. New York: Committee for Economic Development, 1970.

Manne, H.G. and Wallich, H.C., (1972), The modern corporation and social responsibility. Washington, DC: American Enterprise Institute for Public Policy Research.

Elster, J., (1989), "Social Norms and Economic Theory”, Journal of Economic Perspectives, 3, (4).

Carroll, A.B., (1979), “A three-dimensional conceptual model of corporate performance”, The Academy of Management Review (pre-1986), oct, 1979.

Carroll, A. B., (1991), "The Pyramid of Corporate Social Responsibility: Toward the Moral Management of Organizational Stakeholders”, Business Horizons, jul-aug.

Wartick, S. L. and Cochran, P. L., (1985), "The Evolution of the Corporate Social Performance Model”, The Academy of Management Review, Vol. 10, (4), oct, pp. 758-769.

Aupperle, K. E., Carroll, A. B. and Hatfield, J. D., (1985), “An Empirical Examination of the Relationship between Corporate Social Responsibility and Profitability", The Academy of Management Journal, Vol. 28, (2), jun, pp. 446-463.

Cochran, P. L. and Wood, R. A., "Corporate Social Responsibility and Financial Performance”, (1984), The Academy of Management Journal, Vol. 27, (1), march, pp. 42-56.

Drucker, P.F., (1984), “The New Meaning of Corporate Social Responsibility”, 
California Management Review.

Donaldson, T. and Preston, L. E., (1995), "The Stakeholder Theory of the Corporation: Concepts, Evidence, and Implications”, The Academy of Management Review, Vol. 20, (1), jan, pp. 65-91.

Freeman, R. E. and McVea, J., (2001), A Stakeholder Approach to Strategic Management, Darden Business School Working Paper No. 01-02, 2001.

Freeman, R. E., (1984), Strategic Management: A Stakeholder Approach (Pitman). Berle, A. A. and Means, G.C., (1932), The modern corporation and private property, Transaction Publishers.

Evan, W.M. and Freeman, R.E., 1988, A stakeholder theory of the modern corporation: Kantian capitalism. In T. Beauchamp \& N. Bowie (Eds.), Ethical theory and business, pp.75-93. Englewood Cliffs, NJ: Prentice Hall.

Furubotn, E, G. and Pejovich, S., (1972), "Property Rights and Economic Theory: A Survey of Recent Literature", Journal of Economic Literature, 10(4), dec.

Coase, R. H., (1960), “The problem of social cost”, The Journal of Law and Economics, Vol. III, oct.

Stanford Encyclopedia of Philosophy, (2004), Property and Ownership, First published Mon sep 6, 2004.

Becker, L. C., (1992), "Property”, In L. D. Becker and C. B. Becker (Eds.), Encyclopedia of ethics, Vol. 2, pp. 1023-1027, New York: Garland.

Dill, W.R., (1958), "Environment as an influence on managerial autonomy”, Administrative Science Quarterly, 2, pp.409-443.

Aoki, Masahiko, (1984), The co-operative game theory of the firm, Clarendon Press (Oxford Oxfordshire and New York).

Williamson, O., (1985), The economic institutions of capitalism. Firms, markets, relational contracting, Free Press.

Kirman, A.P. (1987), "Pareto as an Economist”, in J. Eatwell, M. Milgate, and P. Newman (eds.), The New Palgrave Dictionary of Economics (London: Macmillan).

Hayek, F. A. (1935), comp., Collectivist Economic Planning: Critical Studies on the Possibilities of Socialism, George Routledge and Sons, London.

Lange, O., “The Computer and the Market” (1967), in C. H. Feinstein, ed., Socialism, Capitalism and Economic Growth, Cambridge University Press.

Hammond, P., (1990), “The Role of Information in Economics”, L'Informazione nell' Economia e nel Diritto (Milan).

Kornai, J., (2000), "What the Change of System From Socialism to Capitalism Does and Does Not Mean", Journal of Economic Perspectives-Vol. 14, (I)-winter - pp. 27-42.

Friedman, M., (1953), “Some Implications for Economic Issues”, Sec. V of The 
Methodology of Positive Economics, University of Chicago Press.

Henderson, D., (2008), “The Case Against "Corporate Social Responsibility””,

Policy, The Globalization Reader. 3rd ed. Ed Lechner, Frank and John Boli. Malden, MA: Blackwell Publishing, pp.202-207.

Berensztein, S., (2012), “La etapa jacobina del kirchnerismo”, Foco Económico, 26 de agosto.

The Economist, (2005), The Good Company, Jan. $20^{\text {th }}$.

Tamames, R. (2001), “A ningún país le viene mal la globalización”, Capital (11), ago.

Smith, A.(1776), An Inquiry into the Nature and Causes of the Wealth of Nations. Book One, Chapter Two, Of the Principle which gives occasion to the Division of Labour.

von Mises, Ludwig, (1920), "Die Wirtschaftsrechnung im sozialistischen Gemeinwesen", Archiv für Sozialwissenschaften, Vol. 47, Traducido como "Economic Calculation in the Socialist Commonwealth”, trad. S. Adler, In Hayek, Friedrich A., (1935), comp., Collectivist Economic Planning: Critical Studies on the Possibilities of Socialism, George Routledge and Sons, London. 